\title{
Food intake and acquisition of maze learning as a function of the experimenter
}

\author{
Sachio Ashida \\ UNIVERSITY OF MICHIGAN
}

\begin{abstract}
Abstraet
Although the results were not statistically significant, a group of rats trained by a naive experimenter showed (a) less food intake, (b) greater loss of body weight, and (c) fewer trials to learn a maze. However, the maze running time of the naive experimenter's rats was significantly slower than that of the other experimenter's rats.
\end{abstract}

\section{Introduetion}

Some research evidence (e.g., Bernstein, 1957; Barry, 1957; Levine, 1957; Ruegamer et al, 1954; Weininger, 1954) indicates that rats given extra handling by the experimenter show significantly greater body weight gains and greater activity than do "unhandled" rats, while other research evidence (e.g., Ader, 1959; Candland et al, 1960; Gertz, 1947; Scott, 1955) indicates no significant difference between handled and unhandled rats in either body weight gain or the amount of activity. Using four different experimenters for acquisition of a conditioned shock avoidance response in rabbits, Brogden (1962) found that a naive experimenter's rabbits showed the slowest conditioning and that the practice effect of the naive experimenter was statistically significant. In our laboratory, naive experimenters were carefully supervised and observed, and their effects upon the rats' conditioned responses were observed fairly consistently. Such effects may be based on the experimenter's handling manner beyond prescribed and agreed standardized experimental procedures, including handling methods. The purpose of this paper is to show such effects of a naive experimenter upon rats' amount of food intake, body weight gain, and acquisition of maze learning.

\section{Method}

This study employed two groups, each of 21 male Sprague-Dawley albino rats, about 90 days old. The rats in Group I were handled and fed by a naive experimenter (a first-year graduate student) and the rats in Group II by an experienced experimenter (this reporter). For the first two weeks, this reporter supervised the naive experimenter's handling ( $5 \mathrm{~min}$. twice daily) and feeding of the rats in order to establish standardized handling methods. After these two weeks, a 23-hr. deprivation schedule was established with a 30-min. feeding time. Water was always available in the cages. The amount of food intake was recorded daily.

After two weeks of the establishment of deprivation schedule, each rat was tested in the modified TolmanHonzik 14-unit maze. The experimental criterion for the acquisition was less than three errors within three consecutive trials. The 23-hr. deprivation schedule was maintained throughout this experiment. One trial per day was given. To assure uniform conditions, both groups of rats were kept in the same room, and the same maze was used. A naive experimenter was checked from time to time in order to maintain standardized procedures.

\section{Results and Diseussion}

The rats in Group II consumed slightly greater amount of wet mash than the rats in Group I, but the difference between the two groups was not statistically significant. For example, the mean weights of wet mash consumed during the first week of the deprivation schedule were $23.1 \mathrm{gm}$ for Group I and $26.6 \mathrm{gm}$ for Group II, $F(1,20)=2.641$; during the second week $32.6 \mathrm{gm}$ for Group I and $37.8 \mathrm{gm}$ for Group II, $F(1,20=3.156$; during the fifth week $39.5 \mathrm{gm}$ for Group I and $42.8 \mathrm{gm}$ for Group II, $\mathrm{F}(1,20)=2.716$.

Using the mean body weight of the second week of pre-experimental handling as the reference weight, i.e., $100 \%$, the mean percentage of body weight was computed. During the first week of deprivation, Group I lost $13.31 \%$ of the reference body weight, Group II $8.01 \%$. The difference was significant beyond the .05 level, $F(1,20)=5.710$. After the second week on, however, the difference between the two groups was not significant. For example, during the second week, Group I lost $15.42 \%$ of the reference body weight and Group II $13.47 \%, F(1,20)=3.056$. During the fifth week, Group I lost $15.22 \%$ of the reference body weight and Group II $14.39 \%, F(1,20)=1.497$ 。

For the maze acquisition, Group I required an average of 18.05 trials and Group II an average of 19.79 trials to satisfy the experimental criterion. The difference was not significant, $F(1,20)=.217$. It was found, however, that the rats in Group I spent more time in the maze than did the rats in Group $\mathrm{II}$. In order to see such a relationship more clearly, the mean munning time from the starting compartment to the goal compartment of the maze with no error, one error, two errors, and so forth, were evaluated. The difference was significant beyond the .05 level, $t=2.359, \mathrm{df}=18$. The results are shown graphically in Fig. 1.

The results of this study suggest that the naive experimenter may have handled the rats differently from the experienced experimenter and may thus have induced an increased emotional effect in the rats. If the difference in handling between the two experimenters were negligible, then the threshold for emotional reactivity should be the same for both groups (e.g., see Bovard's 


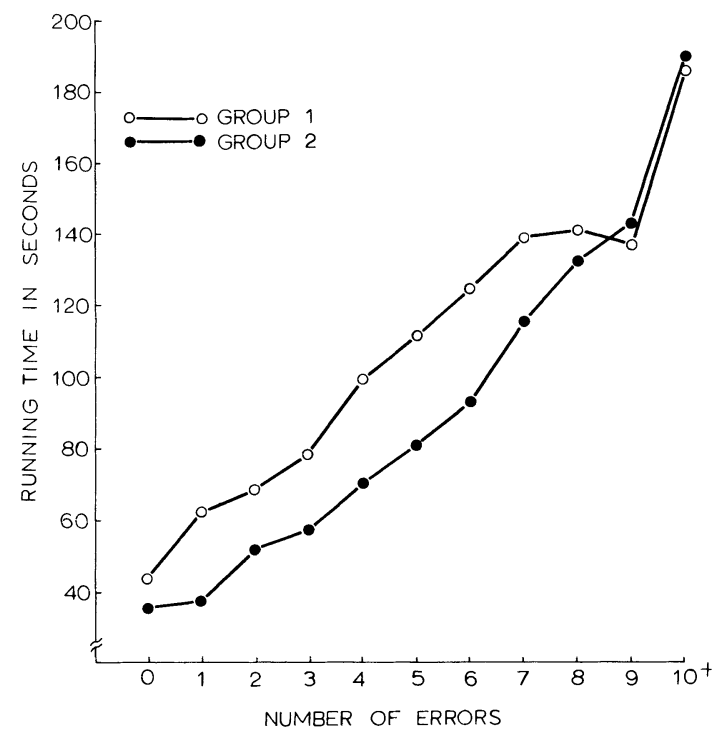

Fig. 1. The mean running time as a function of the number of errors.

hypothesis, 1954). But if this threshold were the same for both groups, then Group I should have shown faster running time and fewer errors than Group II, since Group I's greater body weight loss clearly implies that the drive strength of Group I was higher than that of Group II. But why, then, did the rats in Group I lose more body weight than did the rats in Group II? Adapting Bovard's hypothesis, the answer may be that the naive experimenter's handling did not raise the threshold for emotional reactivity as did the experienced experimenter's. Thus the higher emotionality of rats in Group I induced less food intake and greater body weight loss than those of rats in Group II. During the maze learning, the emotionality of rats in Group I was possibly stronger than the higher drive state elicited by the greater body weight loss. Hence the running times of Group I was greater than that of Group II.
The results of this study do not agree with Brogden's findings (1962) that the animal conditioned by a naive experimenter showed the slowest conditioning. Such a disagreement may be based on (a) use of a different conditioning method, i.e., shock avoidance training for Brogden and maze learning for this study; and (b) use of a different S, i.e., rabbits for Brogden and rats for this study. However, this study clearly suggests that every effort must be made to minimize experimental errors based on handling methods, by means of (1) the use of standardized experimental procedures, (2) sufficient training of a naive experimenter prior to the beginning of the experiment proper, and (3) the use of an appropriate experimental apparatus.

\section{References}

ADER, R. The effects of early experience on subsequent emotionality and resistance to stress. Psychol. Monogr., 1959, 73.

BARRY, H. III. Habituation to handling as a factor in retention of maze performance in rats. J. comp. physiol. Psychol., 1957, 50, 366-367.

BERNSTEIN, L. The effects of variation in handling upon learning and retention. J. comp. physiol. Psychol., 1957, 50, 162-167.

BOVARD, E. W. A theory to account for the effects of early handling on viability of the albino rat. Science, 1954, 120, 187.

BROGDEN, W. J. The experimenter as a factor in animal conditioning. Psychol. Rep., 1962, 11, 239-242.

CANDLAND, D. K., FAULDS, B., THOMAS, D. B., \& CANDLAND, M. H. The reinforceing value of gentling. J. comp. physiol. Psychol., $1960,53,55-58$.

GERTZ, B. The effect of handling at various age levels on emotional behavior of adult rats. J. comp. physiol. Psychol., 1957, 50, 613-616.

LEVINE, S. Infantile experience and resistance to physiological stress. Science, 1957, 126, 405.

RUEGAMER, E. R., BERNSTEIN, L。, \& BENJAMIN, J. D. Growth, food utilization, and thyroid activity in the albino rat as a function of extra handling. Science, 1954, 120, 184-185.

SCOTT, J. H. Some effects at maturity of gentling, ignoring, or shocking rats during infancy. J. abnor. soc. Psychol., 1955, 51, 412-414.

WEININGER, O. Physiological damage under emotional stress as a function of early experience. Science, 1954, 119, 285-286. 